\title{
Eliminating the need for fasting with oral administration of bisphosphonates
}

This article was published in the following Dove Press journal:

Therapeutics and Clinical Risk Management

17 October 2013

Number of times this article has been viewed

\author{
Michael Pazianas' \\ Bo Abrahamsen ${ }^{2,3}$ \\ Serge Ferrari ${ }^{4}$ \\ R Graham G Russell 1,5 \\ 'The Botnar Research Center and \\ Oxford University Institute of \\ Musculoskeletal Sciences, Oxford, \\ UK; ${ }^{2}$ Department of Medicine F, \\ Gentofte Hospital, Hellerup, ${ }^{3}$ Odense \\ Patient data Explorative Network \\ (OPEN) Institute of Clinical Research, \\ University of Southern Denmark, \\ Odense, Denmark; ${ }^{4}$ Division of \\ Bone Diseases, Faculty of Medicine, \\ Geneva University Hospital, Geneva, \\ Switzerland; ${ }^{5}$ Mellanby Centre for \\ Bone Research, University of Sheffield, \\ Sheffield, UK
}

Correspondence: Michael Pazianas The Botnar Research Centre and Oxford University Institute of Musculoskeletal Sciences, Nuffield Department of Orthopaedics, Rheumatology and Musculoskeletal Diseases, Nuffield Orthopaedic Centre, Headington, Oxford OX3 7LD, UK Tel +44 I865 227335

Fax +44 I865 227966

Email michael.pazianas@ndorms.ox.ac.uk

\begin{abstract}
Bisphosphonates are the major treatment of choice for osteoporosis, given that they are attached preferentially by bone and significantly reduce the risk of fractures. Oral bisphosphonates are poorly absorbed (usually less than $1 \%$ for nitrogen-containing bisphosphonates) and when taken with food or beverages create complexes that cannot be absorbed. For this reason, they must be taken on an empty stomach, and a period of up to 2 hours must elapse before the consumption of any food or drink other than plain water. This routine is not only inconvenient but can lead to discontinuation of treatment, and when mistakenly taken with food, may result in misdiagnosis of resistance to or failure of treatment. The development of an enteric-coated delayed-release formulation of risedronate with the addition of the calcium chelator, ethylenediaminetetraacetic acid (EDTA), a widely used food stabilizer, eliminates the need for fasting without affecting the bioavailability of risedronate or its efficacy.
\end{abstract}

Keywords: bisphosphonates, osteoporosis treatment, absorption, EDTA, osteoclasts

\section{Introduction}

Bone loss resulting from unbalanced bone remodeling that favors bone resorption is a major feature of common bone pathologies, such as osteoporosis, Paget's disease, and metastatic bone disease. In most cases, antiresorptive treatment helps to lower excessive resorptive activity to a level that better equates to bone formation and thus reduces the risk of fractures. Bisphosphonates are among the most effective and widely used antiresorptive agents available. ${ }^{1}$ An important and unique advantage of bisphosphonates is their selective uptake by the skeleton, coupled with preferential targeting of sites with increased bone activity. Oral formulations, however, are poorly absorbed (on average usually less than 1\%), and concomitant intake of food or beverage further limits absorption. For this reason, patients treated with oral bisphosphonates are advised to refrain from oral intake (other than plain water) for up to 2 hours following administration of medication. However, it has been found that more than half of patients may ignore these directives. ${ }^{2}$

The overall low oral bioavailability of bisphosphonates, together with the inconvenient routine of keeping the stomach empty for a considerable amount of time, led to the development and success of weekly and monthly regimens, and now to the development of a once-weekly regimen utilizing risedronate $35 \mathrm{mg}$ delayed-release (DR), to which the well known chelating compound ethylenediaminetetraacetic acid (EDTA) has been added. This allows patients the option to take the tablet before or following a meal. This regimen has been approved in the US for administration after a meal as a new drug (due to the addition of EDTA) under the brand name Atelvia ${ }^{\circledR}$, 
and in Canada as Actonel $\mathrm{DR}^{\circledR}$, whilst in Australia it has been licensed as Actonel $\mathrm{EC}^{\circledR}$ (enteric-coated tablets) for administration before and after breakfast.

\section{Structure and pharmacology of bisphosphonates}

Bisphosphonates are chemical compounds with a high affinity for bone mineral and therefore bind tightly to the exposed mineral surfaces of bone. At sites of bone formation, the newly deposited bisphosphonate becomes buried when additional bone is deposited on top. During the process of bone resorption, osteoclasts on the bone surface release acid and enzymes that resorb the mineralized matrix. In bisphosphonate-coated bone, osteoclasts encounter the chemical compound and ingest it, leading to their inactivation and possible death by apoptosis. ${ }^{3}$

Bisphosphonates are modified analogs of inorganic pyrophosphate structures where the oxygen connecting the two phosphate groups (P-O-P) is replaced by a carbon atom (P-C-P), as shown in Figure $1 .{ }^{4}$ As a result, bisphosphonates are resistant to chemical and enzymatic degradation.
The addition of nitrogen in their structure (N-BPs) enhances their binding affinity and antiresorptive potency. Non-N-BPs, such as tiludronate, are little used today, whereas etidronate and clodronate are still sometimes prescribed to patients with osteoporosis or metastatic bone disease, respectively. The N-BPs in oral (alendronate, risedronate, ibandronate) or parenteral (intravenous) preparations (ibandronate, pamidronate, and zoledronate) act on the same pathway, ie, the mevalonate pathway, as the cholesterol-lowering drugs (statins) albeit downstream (Figure 2). ${ }^{4}$ They inhibit the farnesyl pyrophosphate synthase enzyme, thereby preventing prenylation (lipid modification) of many small GTPases, such as Ras, Rab, Rho, and Rac, a large group of signaling proteins that are critical for the function and survival of osteoclasts. ${ }^{3}$

\section{Bisphosphonates reaching osteoclasts}

\section{Enteric absorption of bisphosphonates}

Oral formulations, especially the N-BPs, are poorly absorbed $(\sim 1 \%)^{5}$ and their bioavailability may be negligible if taken

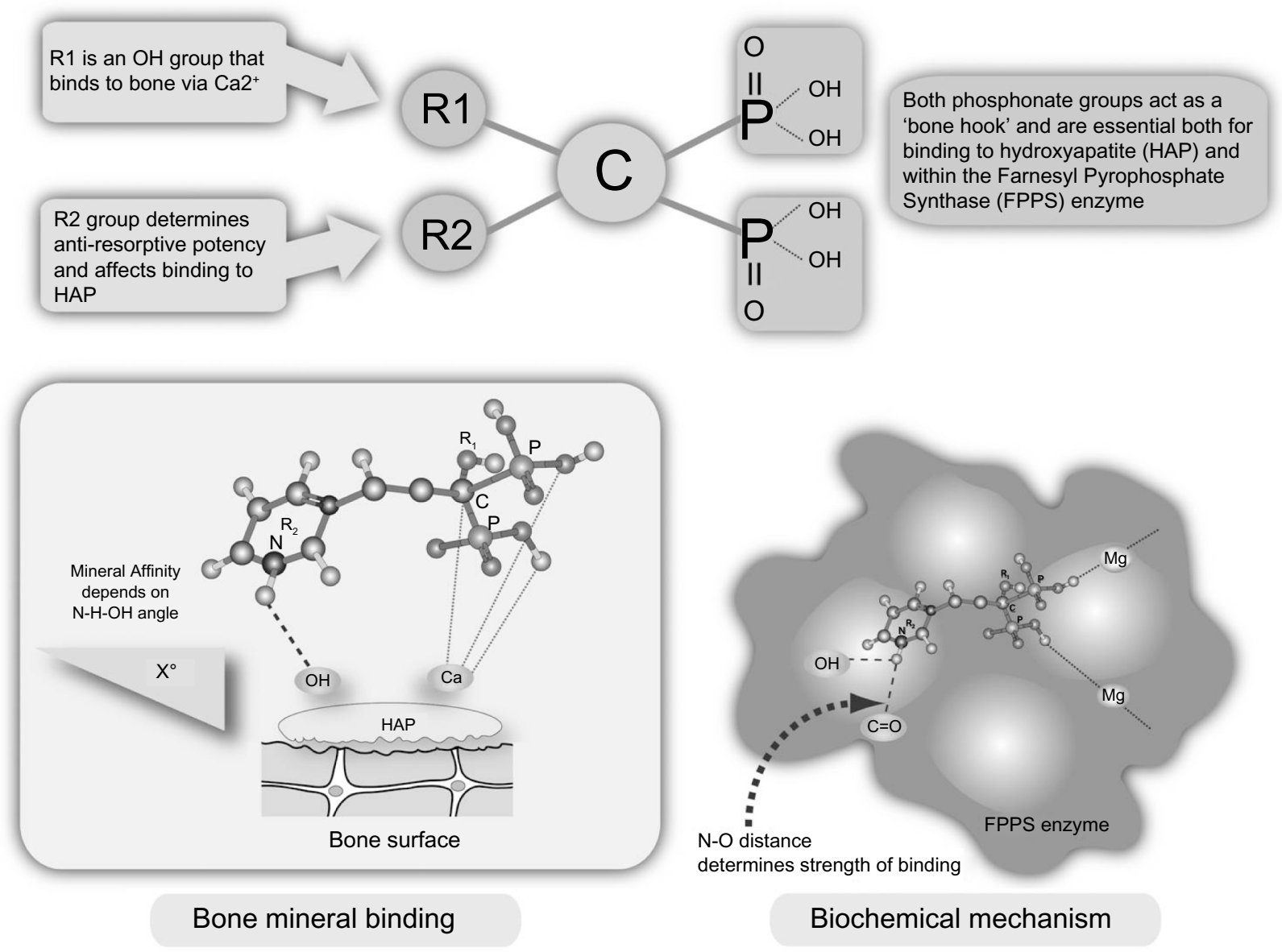

Figure I Bisphosphonate structure, bone mineral binding, and biochemical mechanisms.

Note: Reproduced from Pazianas M, Compston J, Huang CL-H. Atrial fibrillation and bisphosphonate therapy. J Bone Miner Res. 2010;25:2-I0. ${ }^{4}$ With permission of the American Society for Bone and Mineral Research. 


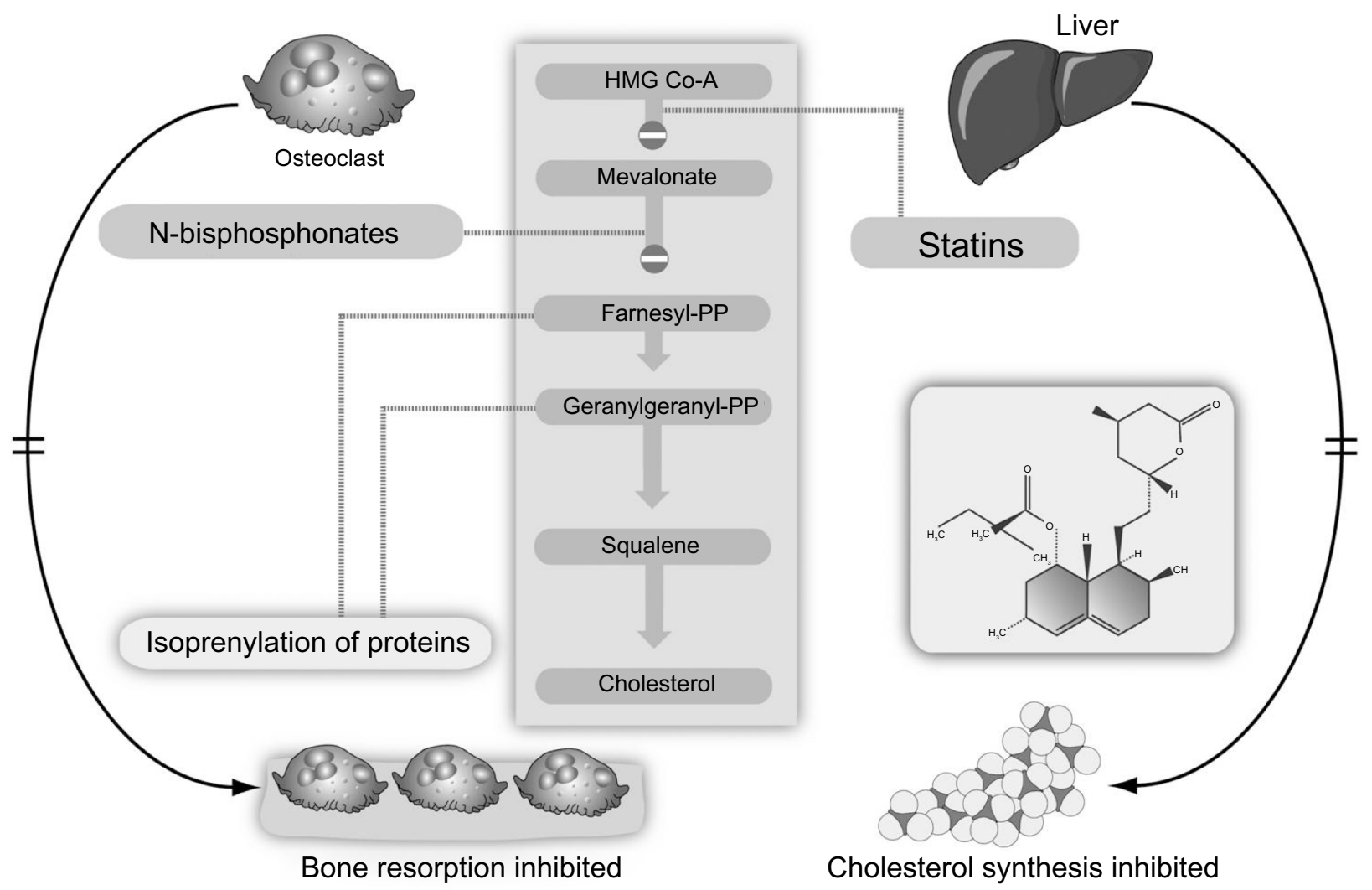

Figure 2 Inhibition of the mevalonate pathway by statins and bisphosphonates.

Note: Reproduced from Pazianas M, Compston J, Huang CL-H. Atrial fibrillation and bisphosphonate therapy. J Bone Miner Res. 20I0;25:2-I0. ${ }^{4}$ With permission of the American Society for Bone and Mineral Research.

Abbreviation: HMG Co-A, 3-hydroxy-3-methylglutarylcoenzyme A.

on a full stomach. This may be due to the formation of insoluble chelates with elements such as calcium, magnesium, and aluminum, which are naturally present in many foods and liquids, but other mechanisms may be important. For these reasons, bisphosphonates must be taken before breakfast, with no subsequent food/beverage intake for at least 30 minutes and often longer. At the other end of the spectrum, commonly used medications such as proton pump inhibitors, which work by reducing the secretion of gastric acid, effectively elevate gastric $\mathrm{pH}$, and may have the effect of increasing bisphosphonate bioavailability. ${ }^{6,7}$ Although some non-N-BPs can be metabolized intracellularly to cytotoxic adenosine triphosphate analogs, in general bisphosphonates are excreted in the urine unmetabolized. Moderate or severe renal impairment therefore may increase plasma concentrations, and their use is not recommended in patients with creatinine clearance less than $30 \mathrm{~mL}$ per minute.

Our current understanding is that bisphosphonates are likely to be absorbed throughout the intestine, although more effectively in segments with comparatively larger surface areas (jejunum $>$ duodenum $>$ ileum). ${ }^{8}$ Studies using pamidronate and tiludronate on human intestinal epithelial CaCo-2 cells ${ }^{9,10}$ and alendronate in a rat model ${ }^{8}$ suggest that bisphosphonates find their way into the systemic circulation through the paracellular and not the transcellular route (Figure 3). More specifically, bisphosphonates reach the bloodstream through the tight junctions connecting epithelial cells and pores permeable to molecules up to a molecular weight of 150. Bisphosphonates, however, are in the 200-400 molecular weight range, which limits

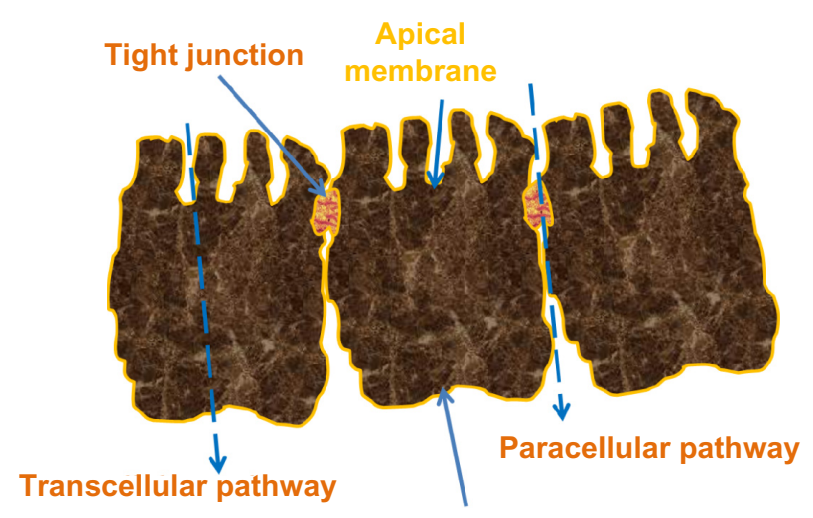

Basolateral membrane

Figure 3 Paracellular, transcellular route, and tight junctions. 
effective absorption. ${ }^{11,12}$ Additionally, divalent ions, such as calcium and magnesium, are crucial for the function of tight junctions. Divalent cations bind strongly to all bisphosphonates, including N-BPs, and form chelates. Further, the lack of transcellular crossing coupled with the considerable hydrophobicity of the lining of the small intestine (and gastric and colonic mucosa) serves as a further limiting factor to the absorption of hydrophilic oral N-BPs, such as alendronate and risedronate.

\section{Bisphosphonate uptake by osteoclasts}

Osteoclasts ingest bisphosphonates via fluid phase endocytosis, while two other modes of uptake, ie, adsorptive and receptor-mediated endocytosis, are probably not involved. ${ }^{13}$ This fluid phase endocytosis is a low-efficiency and nonspecific process characterized by bulk uptake of solutes in exact proportion to their concentration in extracellular fluid. ${ }^{14}$

\section{Fasting and its effects on adherence (persistence/compliance)}

Using the concepts of persistence (how long a patient continues therapy), compliance (how correctly, in terms of dose and frequency, a patient takes the medication), and adherence (a combination of persistence and compliance), ${ }^{15}$ it is possible to quantify their impact on treatment outcomes. Generally, the adherence rate for prescribed medications could be as low as $0 \%$, with an average of $50 \%$ for medications used in several chronic diseases. ${ }^{16}$ Low adherence could be mischaracterized as treatment failure and could lead to unnecessary and potentially harmful treatment modifications. ${ }^{17}$

Interestingly, improving adherence does not increase the incidence of adverse events. ${ }^{18}$ In the case of osteoporosis, where the condition is asymptomatic and medication is taken primarily to prevent long-term skeletal complications, it has been estimated that one third to one half of patients do not take their medication as directed, and nonadherence may begin soon after treatment initiation. ${ }^{15}$ Even in countries reporting relatively good persistence with osteoporosis treatment, the mean persistence on oral bisphosphonates is only about 3 years. ${ }^{19}$

Treatment response is related to the dosage and administration of a therapy. The need to fast has been identified among the top three issues reported by patients as the reason for poor adherence ${ }^{20}$ (Figure 4). The inconvenience is obvious because overnight fasting prior to taking the medication and continuing for up to 2 hours afterwards could severely disrupt daily routines. Therefore, development of a formulation that would allow the patient to take the medication following breakfast is expected to improve adherence. ${ }^{21}$

\section{Overcoming the fasting hurdle}

Prevention of bisphosphonates from forming insoluble complexes with calcium and other divalent or trivalent cations present in food was found to be key to overcoming the fasting requirement. Therefore, use of chelating agents such as EDTA, which is commonly used as an antidote to

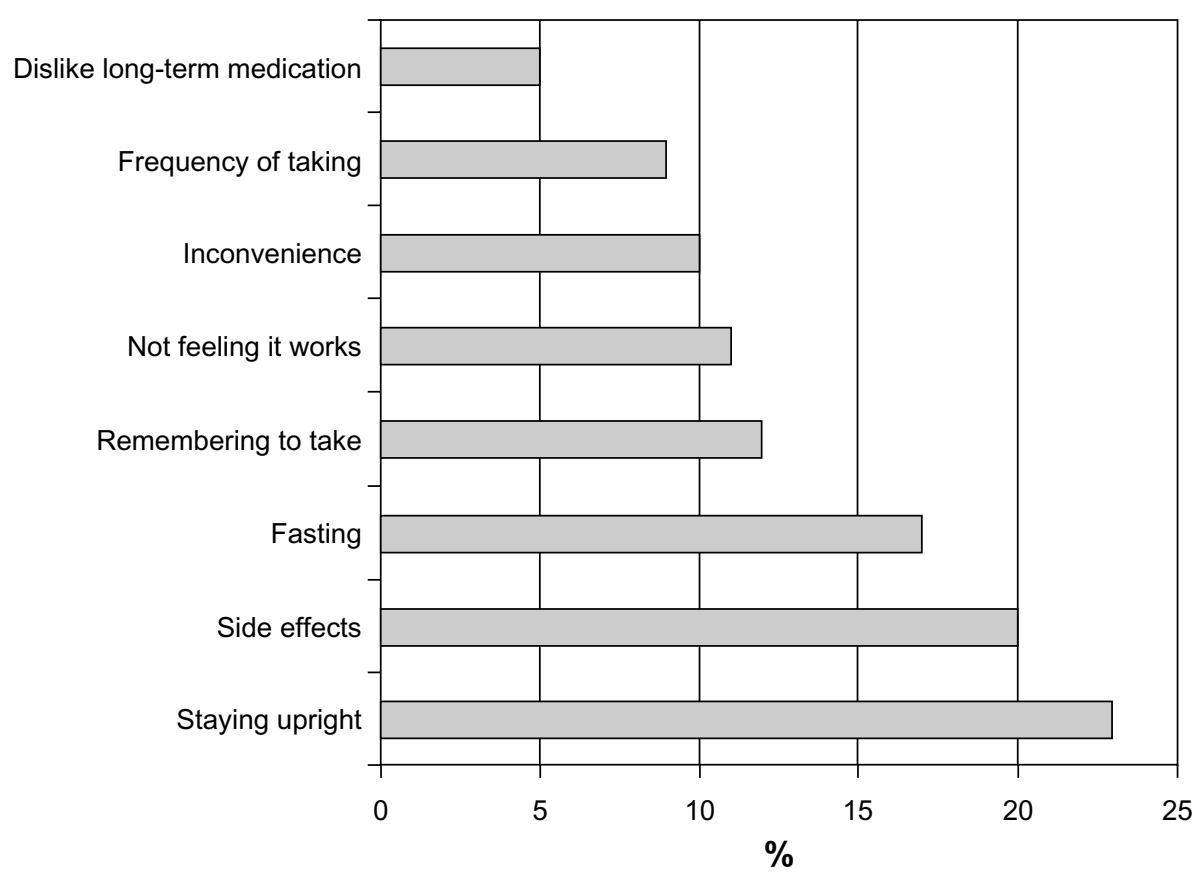

Figure 4 Fasting has been identified as one of the three main reasons for discontinuing treatment.

Note: Reproduced with permission from International Osteoporosis Foundation. The adherence gap: why osteoporosis patients don't continue with treatment. ${ }^{20}$ 
metal toxicity ${ }^{22}$ in humans and extensively as a preservative in foods, ${ }^{23}$ has been explored.

Like bisphosphonates, chelating agents such as EDTA are poorly absorbed. Of orally consumed EDTA, for example, only $5 \%$ or less is absorbed and is almost entirely excreted unchanged in the urine (95\%) within 72 hours. ${ }^{24}$ The low bioavailability of EDTA, however, becomes advantageous when a local but not systemic effect is desired. Indeed, coadministration of EDTA with an oral bisphosphonate could ensure that calcium and other divalent or trivalent cations present in the food would be preferentially bound by the chelating agent and not by the bisphosphonate.

Furthermore, EDTA could enhance permeability by acting as a chelator of tight junction calcium ions, thereby widening the paracellular tight junctions, resulting in better absorption of bisphosphonate. This concept was tested in the early 1990s. ${ }^{25}$ Alendronate or clodronate were given subcutaneously or by mouth together with EDTA in aqueous solution at neutral $\mathrm{pH}$ in a rat model of hypercalcemia. Absorption was increased by about ten-fold in animals treated with $0.6 \mathrm{mg} / \mathrm{kg}$ alendronate and decreased to two-fold with lower doses. The minimal effective dose for EDTA was estimated at $10 \mathrm{mg} / \mathrm{kg}$ for the alendronate-treated animals and $100 \mathrm{mg} / \mathrm{kg}$ for those treated with clodronate. However, the amount of EDTA required to achieve these increases was deemed clinically unacceptable..$^{25}$

Today, we are able to use amounts of EDTA that are effective and clinically safe following the development of a tablet that protects the drug from gastric release and allows relatively rapid release in the small intestine $(\mathrm{pH}>5.5)$, where the concentrations of calcium and other divalent or trivalent cations are anticipated to be lower than in the fed stomach. Therefore, the amount of EDTA required to bind free cations present in the region of drug release should be less. This advance led to the development of an oral, once-weekly $35 \mathrm{mg}$ risedronate DR formulation with a $\mathrm{pH}$ trigger of 5.5, combined with $100 \mathrm{mg}$ EDTA. The lag time (time for initial tablet opening) is usually 10 minutes and not more than 15 minutes. Dissolution is mostly complete ( $>95 \%$ ) at 45 minutes. The coating of the tablet withstands prolonged exposure (16 hours) up to $\mathrm{pH}$ 5.0, thus preventing premature release in the stomach in cases of prolonged gastric retention and/or increased gastric $\mathrm{pH}$. Further, the disintegration time is $4-12$ times longer for the DR tablet than for the immediate-release (IR) tablet, and thus the potential would be less for disintegration of the DR tablet within the esophagus, where the environment is neutral, if transit time is delayed leading to esophageal exposure to risedronate. In this new formulation, the bioavailability of the risedronate $35 \mathrm{mg}$ DR tablet is not markedly affected by the type of food administered at breakfast (typical or high-fat). The time to peak concentration for the $35 \mathrm{mg}$ risedronate DR formulation tablet is $\sim 3$ hours when administered in the morning 4 hours prior to a meal. Its bioavailability is decreased by $\sim 30 \%$ when administered after a high-fat breakfast, but is still similar or 2-4-fold greater when compared with the $35 \mathrm{mg}$ IR tablet administered 30 minutes prior to a high-fat breakfast. It is worth adding that when both formulations were administered after an overnight fast and followed by a 4-hour fast, systemic exposure for the $35 \mathrm{mg}$ DR formulation was approximately $44 \%$ greater than that for the $35 \mathrm{mg}$ IR formulation (data on file, Procter \& Gamble, 2009).

Plasma protein binding of risedronate in humans averages about $24 \%$. Approximately $60 \%$ of the dose is distributed to bone and the remainder of the dose is excreted in the urine. The renal clearance is not concentration-dependent, and there is a linear relationship between renal and creatinine clearance. The renal clearance of risedronate was decreased by about $70 \%$ in patients with a creatinine clearance of approximately $30 \mathrm{~mL}$ per minute as compared with persons with normal renal function. The $35 \mathrm{mg}$ risedronate DR formulation is not recommended for use in patients with severe renal impairment (creatinine clearance less than $30 \mathrm{~mL}$ per minute), but no dose adjustment is necessary for higher creatinine clearances. Also, dosage adjustment is unlikely to be needed in patients with hepatic impairment. Unabsorbed drug is eliminated unchanged in feces. ${ }^{26}$

The risedronate $35 \mathrm{mg}$ DR once-weekly tablet also contains $100 \mathrm{mg}$ EDTA. This is less than the acceptable daily intake $(2.5 \mathrm{mg} / \mathrm{kg}$ as the calcium, disodium salt, which equates to $149 \mathrm{mg}$ /day for a $60 \mathrm{~kg}$ person). It is expected to sequester a relatively small amount of calcium (approximately $10 \mathrm{mg}$ ) from the gastrointestinal tract. There is also no impact on solubility, and hence the absorption of coadministered drugs. Further, in patients treated with risedronate $35 \mathrm{mg}$ DR immediately following a standard meal and a proton pump inhibitor such as omeprazole or $600 \mathrm{mg}$ calcium/400 IU vitamin D supplement, the bioavailability of risedronate was similar to that of the $35 \mathrm{mg}$ IR tablet given at least 30 minutes before breakfast (data on file, Procter \& Gamble, 2009). However, gastric acid-suppressive agents (antacids), calcium supplements, magnesium-based supplements or laxatives, and iron preparations should be taken at a different time of the day. ${ }^{26}$

\section{Clinical data: once a week risedronate $35 \mathrm{mg}$ DR}

A randomized, double-blind, active-controlled, parallelgroup study assessed the safety and efficacy of risedronate 

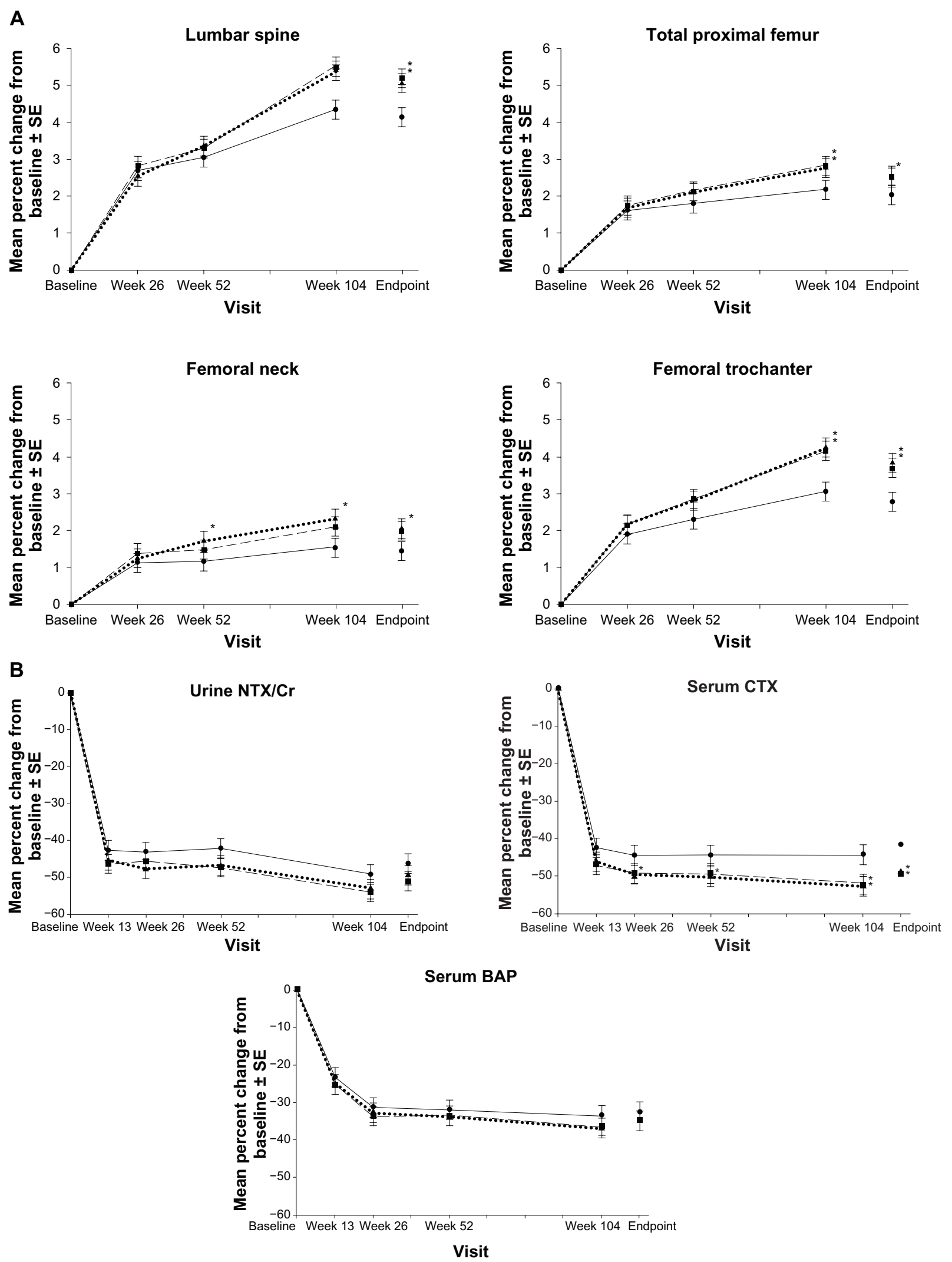

Figure 5 Mean percent change from baseline \pm standard error of the mean in (A) bone mineral density and (B) bone turnover markers over 2 years in women receiving risedronate $5 \mathrm{mg}$ immediate-release daily (solid lines with black circles), $35 \mathrm{mg}$ delayed-release immediately following breakfast weekly (dashed lines with black squares), or $35 \mathrm{mg}$ delayed-release at least 30 minutes before breakfast weekly (circle dashed lines with black triangles). Asterisk represents statistically significant difference between immediate-release daily and delayed-release weekly treatment group.

Note: With kind permission from Springer Science+Business Media: McClung MR, Balske A, Burgio DE, Wenderoth D, Recker RR. Treatment of postmenopausal osteoporosis with delayed-release risedronate $35 \mathrm{mg}$ weekly for 2 years. Osteoporos Int. 20I3;24:30I-310. ${ }^{29}$

Abbreviations: CTX, C-terminal telopeptide; SE, standard error of the mean; CR, creatinine; BAP, bone alkaline phosphatase. 
$35 \mathrm{mg}$ DR weekly in a "noninferiority" test ${ }^{27}$ during the first year of a 2-year study. ${ }^{28}$ The "noninferiority" or "bridging" investigational approach has been used as a realistic substitute for mandatory antifracture studies involving approved daily oral bisphosphonate regimens when seeking approval for new intermittent administration (weekly or monthly regimens). The requirement in these cases has been bone mineral density (BMD) and bone turnover marker comparisons with the daily oral regimens and proof of "noninferior" outcomes. Fracture data are being collected as adverse effects. ${ }^{28}$

In total, 767 postmenopausal osteoporotic women with lumbar spine or total hip BMD corresponding to a T-score of -2.5 or lower or a T-score of -2.0 or lower with at least one prevalent vertebral fracture (T4-L4) completed 12 months of the study. They had been allocated to one of three groups, two of them treated with once-weekly risedronate $35 \mathrm{mg}$ DR either at least 30 minutes before (delayed-response before breakfast [DRBB], $\mathrm{n}=258$ ) or immediately following breakfast (delayed-response following breakfast [DRFB], $\mathrm{n}=252$ ) and the third one treated with the established regimen of $5 \mathrm{mg}$ risedronate IR daily before breakfast ( $\mathrm{n}=257$ ) according to US Food and Drug Administration requirements.

The percent change from baseline in lumbar spine BMD was the primary end point. At the end of year one, the mean percent changes (increase) in BMD and bone turnover markers (decrease) were similar across groups. The occurrence of new incident morphometric vertebral fracture was very low and remarkably similar in the three groups. Overall, the efficacy of once-weekly risedronate $35 \mathrm{mg}$ DR administered before or following breakfast was noninferior to that of risedronate $5 \mathrm{mg}$ IR daily. The same pattern was observed in the adverse effects/tolerability profile of once-weekly risedronate $35 \mathrm{mg}$ DR, with no significant differences between groups. Participants dropped out of the study in similar proportions across treatment groups. This is not an unexpected finding in randomized controlled trials, and may not be interpreted as nonimproved adherence in the once-weekly risedronate $35 \mathrm{mg}$ DR group. The incidence of upper gastrointestinal adverse events (upper abdominal pain) in the DRBB group and lower gastrointestinal adverse events (mild to moderate diarrhea) in the DRFB group were numerically but not statistically higher. Small transient decreases in serum calcium provoking reciprocal changes in total PTH (1-84) were recorded in the first few weeks of treatment in the groups receiving DR-EDTA, but ran their course without causing any clinical symptomatology.

A total of 722 participants completed 2 years of treatment. ${ }^{29}$ Both groups receiving weekly DR risedronate demonstrated BMD increases at the lumbar spine and total hip similar to or greater than that with the risedronate $5 \mathrm{mg}$ IR daily dose group (Figure 5A). Decreases in bone turnover markers were similar or significantly lower in the weekly risedronate DR groups (Figure 5B). The noninferiority of risedronate DR, further supported by bone histomorphometric data (the "gold standard" in assessing bone structure and function). After 2 years of treatment, bone-forming activity (presence of double tetracycline label) was evident in all 45 samples examined.

Histomorphometric measurements (static and dynamic) and parameters of bone mineralization were similar across treatment groups. These findings are in line with those reported after 1,3 , and 5 years of treatment with $5 \mathrm{mg}$ risedronate IR daily in postmenopausal women, providing assurance that the weekly $35 \mathrm{mg}$ risedronate DR does not cause excessive reduction of bone turnover. In patients treated with other antiresorptive medications, such as alendronate or denosumab (antibody to RANK ligand), tetracycline labels have been hard to find in many subjects. ${ }^{30,31}$ Finally, new incident morphometric vertebral fractures were not significantly different between the DR and IR groups (five in the IR daily group, two in the DRFB weekly group, and six in the DRBB weekly group).

\section{Conclusion}

The DR formulation of risedronate has simplified the dosing regimen for bisphosphonates without compromising clinical efficacy, and probably improving it, based on BMD evidence. Avoiding the inconvenience of fasting should motivate osteoporotic patients to take their treatment for longer and therefore may improve poor adherence rates of bisphosphonate use. Further studies are required to confirm this.

\section{Author contributions}

All authors made substantial contributions to the conception, design, drafting, reading, and editing of this paper, and approved the final manuscript.

\section{Disclosure}

MP is a consultant to the Alliance for Better Bone Health and Warner Chilcott. BA serves on advisory boards for Nycomed and Amgen, and has received speakers fees from Nycomed, Eli Lilly, Amgen, and MSD, and has had research contracts with NPS Pharma, Amgen, and Novartis. SF has consulted and served on advisory boards for MSD, Amgen, GSK, Eli Lilly, Novartis, and Pfizer (Switzerland), has received research grants from MSD and Amgen, and lecture fees from MSD, Amgen, GSK, Eli Lilly, Novartis, Servier, 
Sanofi, Warner Chilcott, Roche (Switzerland), and Pfizer. RGGR has received research support from Sanofi-Aventis and Warner Chilcott, and undertaken consultant/speaker and legal activities with Amgen, Chronos, GlaxoSmithKline, Roche, Procter and Gamble, Sanofi-Aventis, Novartis, Eli Lilly, and Warner Chilcott.

\section{References}

1. Pazianas M, Cooper C, Ebetino FH, Russell RGG. Long-term treatment with bisphosphonates and their safety in postmenopausal osteoporosis. Ther Clin Risk Manag. 2010;6:325-343.

2. Ettinger B, Pressman A, Schein J, Chan J, Silver P, Connolly N. Alendronate use among 812 women: prevalence of gastrointestinal complaints, noncompliance with patient instructions, and discontinuation. J Manag Care Pharm. 1998;4:488-492.

3. Russell RG, Watts NB, Ebetino FH, Rogers MJ. Mechanisms of action of bisphosphonates: similarities and differences and their potential influence on clinical efficacy. Osteoporos Int. 2008;19: 733-759.

4. Pazianas M, Compston J, Huang CL-H. Atrial fibrillation and bisphosphonate therapy. J Bone Miner Res. 2010;25:2-10.

5. Mitchell DY, Barr WH, Eusebio RA, et al. Risedronate pharmacokinetics and intra- and inter-subject variability upon single-dose intravenous and oral administration. Pharm Res. 2001;18:166-170.

6. Porras AG, Holland SD, Gertz BJ. Pharmacokinetics of alendronate. Clin Pharmacokinet. 1999;36:315-328.

7. Dunn CJ, Goa KL. Risedronate: a review of its pharmacological properties and clinical use in resorptive bone disease. Drugs. 2001;61: $685-712$.

8. Lin JH, Chen IW, deLuna FA. On the absorption of alendronate in rats. J Pharm Sci. 1994;83:1741-1746.

9. Boulenc, X, Marti E, Joyeux H, et al. Importance of the paracellular pathway for the transport of a new bisphosphonate using the human CACO 2 monolayers model. Biochem Pharmacol. 1993;46: $1591-1600$.

10. Twiss IM, de Water R, den Hartigh J. Cytotoxic effects of pamidronate on monolayers of human intestinal epithelial (Caco-2) cells and its epithelial transport. J Pharm Sci. 1994;83:699-703.

11. Lin JH. Bisphosphonates: a review of their pharmacokinetic properties. Bone. 1996;18:75-85.

12. Ruifrok PG, Mol WE. Paracellular transport of inorganic and organic ions across the rat ileum. Biochem Pharmacol. 1983;32: 637-640.

13. Thompson K, Rogers MJ, Coxon FP, Crockett JC. Cytosolic entry of bisphosphonate drugs requires acidification of vesicles after fluid-phase endocytosis. Mol Pharmacol. 2006;69:1624-1632.

14. Khalil IA, Kogure K, Akita H, Harashima H. Uptake pathways and subsequent intracellular trafficking in nonviral gene delivery. Pharmacol Rev. 2006;58:32-45.

15. Kothawala P, Badamgarav E, Ryu S, Miller RM, Halbert RJ. Systematic review and meta-analysis of real-world adherence to drug therapy for osteoporosis. Mayo Clin Proc. 2007;82:1493-1501.
16. Sackett DL, Snow JC. The magnitude of adherence and nonadherence. In: Haynes RB, Taylor DW, Sackett DL, editors. Compliance in Health Care. Baltimore, MD: Johns Hopkins University Press; 1979.

17. Stephenson J. Noncompliance may cause half of antihypertensive drug "failures". JAMA. 1999;282:313-314.

18. Viswanathan M, Golin CE, Jones CD, et al. Medication Adherence Interventions: Comparative Effectiveness. Closing the Quality Gap: Revisiting the State of the Science. Evidence Report No 208. (Prepared by RTI International-University of North Carolina Evidence-based Practice Center under Contract No 290-2007-10056-I.) AHRQ Publication No 12-E010-EF. Rockville, MD: Agency for Healthcare Research and Quality; 2012. Available from: http://www.effectivehealthcare. ahrq.gov/reports/final.cfm. Accessed September 12, 2013.

19. Hansen C, Pedersen BD, Konradsen H, Abrahamsen B. Anti-osteoporotic therapy in Denmark - predictors and demographics of poor refill compliance and poor persistence. Osteoporos Int. 2013;24:2079-2097.

20. International Osteoporosis Foundation. The adherence gap: why osteoporosis patients don't continue with treatment. Available from: http://www.iofbonehealth.org/sites/default/files/PDFs/adherence_gap_ report_2005.pdf. Accessed September 12, 2013.

21. Adachi, R, Josse R, Russell RG. If you don't take it - it can't work: the consequences of not being treated or nonadherence to osteoporosis therapy. Ther Clin Risk Manag. 2011;7:181-198.

22. Blanusa M, Varnai VM, Piasek M, Kostial K. Chelators as antidotes of metal toxicity: therapeutic and experimental aspects. Curr Med Chem. 2005;12:2771-2794.

23. Whittaker P, Vanderveen JE, Dinovi MJ, Kuznesof PM, Dunkel VC. Toxicological profile, current use, and regulatory issues on EDTA compounds for assessing use of sodium iron EDTA for food fortification. Regul Toxicol Pharmacol. 1993;18:419-427.

24. Foreman H, Trujillo T. The metabolism of $\mathrm{C} 14$ labeled ethylene diamino tetraacetic acid in human beings. $J$ Lab Clin Med. 1954;43:566-571.

25. Janner M, Mühlbauer RC, Fleisch H. Sodium EDTA enhances intestinal absorption of two bisphosphonates. Calcif Tissue Int. 1991;49:280-283.

26. Atelvia monograph. Available from: http://www.wcrx.com/pdfs/pi/ pi_atelvia.pdf. Accessed September 12, 2013.

27. Pazianas M, Epstein S, Zaidi M. Evaluating the antifracture efficacy of bisphosphonates. Rev Recent Clin Trials. 2009;4:122-130.

28. McClung MR, Miller PD, Brown JP, et al. Efficacy and safety of a novel delayed-release risedronate $35 \mathrm{mg}$ once-a-week tablet. Osteoporos Int. 2012;23:267-276.

29. McClung MR, Balske A, Burgio DE, Wenderoth D, Recker RR. Treatment of postmenopausal osteoporosis with delayed-release risedronate $35 \mathrm{mg}$ weekly for 2 years. Osteoporos Int. 2013;24:301-310.

30. Chavassieux PM, Arlot ME, Reda C, Wei L, Yates AJ, Meunier PJ. Histomorphometric assessment of the long-term effects of alendronate on bone quality and remodeling in patients with osteoporosis. $J$ Clin Invest. 1997;100:1475-1480.

31. Reid IR, Miller PD, Brown JP, et al; Denosumab Phase 3 Bone Histology Study Group. Effects of denosumab on bone histomorphometry: the FREEDOM and STAND studies. J Bone Miner Res. 2010;25: 2256-2265.
Therapeutics and Clinical Risk Management

\section{Publish your work in this journal}

Therapeutics and Clinical Risk Management is an international, peerreviewed journal of clinical therapeutics and risk management, focusing on concise rapid reporting of clinical studies in all therapeutic areas, outcomes, safety, and programs for the effective, safe, and sustained use of medicines. This journal is indexed on PubMed Central, CAS,

\section{Dovepress}

EMBase, Scopus and the Elsevier Bibliographic databases. The manuscript management system is completely online and includes a very quick and fair peer-review system, which is all easy to use. Visit $\mathrm{http}: / /$ www.dovepress.com/testimonials.php to read real quotes from published authors. 